\title{
PENGARUH SUHU EMPAT MUSIM TERHADAP PERHITUNGAN EXERGI PADA TURBIN UAP
}

\author{
MUHAMMAD RISYAD NAUFAL, CUKUP MULYANA* \\ Departemen Fisika, \\ Fakultas Matematika dan Ilmu Pengetahuan Alam, Universitas Padjadjaran \\ Jl. Raya Bandung-Sumedang Km 21, Jatinangor 45363 \\ *email :c.mulyana55@yahoo.com
}

\begin{abstract}
Abstrak. Pembangkit Listrik Tenaga Uap adalah jenis pembangkit listrik tenaga termal yang banyak digunakan di Indonesia karena bahan bakarnya mudah didapat sehingga pembangkit jenis ini menjadi pilihan utama. Salah satu komponennya adalah turbin. Pada artikel ini, dilakukan perhitungan mengenai besar exergi yang dibawa oleh uap yang ada pada turbin. Exergi pada pembangkit awalnya tinggi, namun karena ireversibilitas, terjadi rugi energi dan terdapat efek peningkatan entropi dari lingkungan, hingga pembangkit tidak lagi efektif untuk dioperasikan. Pada hal ini, lingkungan berperan terhadap exergi. Oleh karena itulah seharusnya dilakukan perhitungan berdasarkan exerginya, yaitu kemampuan untuk melakukan kerja berdasarkan teoritis. Salah satu kasusnya berada pada negara dengan empat musim. Dimana setiap musim akan mengalami suhu berbeda-beda untuk setiap musim. Dilakukannlah perhitungan nilai exergi yang ada pada turbin untuk setiap musim yang berbeda-beda. Didapatkan untuk musim dingin, nilai exergi adalah $690.751 \mathrm{kj} / \mathrm{kg}$ dengan exergi hilang 121.204 $\mathrm{kj} / \mathrm{kg}$ dan efisiensi $81.942 \%$. Pada musim panas, nilai exergi adalah $694.354 \mathrm{kj} / \mathrm{kg}$ dengan exergi hilang $129.547 \mathrm{kj} / \mathrm{kg}$ dan efisiensi $80.936 \%$. Pada musim semi, nilai exergi adalah $692.804 \mathrm{kj} / \mathrm{kg}$ dengan exergi hilang $125.959 \mathrm{kj} / \mathrm{kg}$ dan efisiensi $81.365 \%$. Pada musim gugur, nilai exergi adalah $693.645 \mathrm{kj} / \mathrm{kg}$ dengan exergi hilang 127.904 $\mathrm{kj} / \mathrm{kg}$ dan efisiensi $81.132 \%$.
\end{abstract}

Kata kunci : PLTU, Turbin Uap, Exergi, Irreversibilitas, Exergi Destruction.

\begin{abstract}
Steam Power Plant is a type of thermal power plant that is widely used in Indonesia because the fuel is easy to obtain, so this type of generator becomes the main choice. One of its component is turbine. We calculated the exergy carried by the steam in the turbine. Exergy of power plant is initially high, but due to irreversibility, there is an energy loss and an increased entropy effect from environment, until the plant is no longer effective to operate. The environment contributes to exergy. Therefore it should be calculated based on the exergy, namely the ability to perform work based on theoretical. One of the cases is in a country with four seasons. Where each season will experience different suhues for each season. Calculate the exergy values present in the turbine for each different season. For winter, exergy value is $690,751 \mathrm{kj} / \mathrm{kg}$ with exergy destruction is $121,204 \mathrm{kj} / \mathrm{kg}$ and efficiency $81.942 \%$. In summer, exergy value is $694,354 \mathrm{kj} / \mathrm{kg}$ with exergy destruction is $129,547 \mathrm{kj} / \mathrm{kg}$ and efficiency $80.936 \%$. In spring, exergy value is $692,804 \mathrm{kj} / \mathrm{kg}$ with exergy destruction is $125,959 \mathrm{kj} / \mathrm{kg}$ and efficiency $81.365 \%$. In autumn, exergy value is $693,645 \mathrm{kj} / \mathrm{kg}$ with exergy destruction $127,904 \mathrm{kj} / \mathrm{kg}$ and efficiency $81.132 \%$.
\end{abstract}

Keywords : PLTU, Steam Turbine, Exergy, Irreversibility, Exergy Destruction.

\section{Pendahuluan}

PLTU adalah salah satu pembangkit yang banyak dipakai di Indonesia. Itu dikarenakan pada PLTU, bahan bakar yang digunakan relatif mudah untuk didapatkan. Dalam perhitungan efisiensi dari segi keseluruhan PLTU ataupun per- 
komponennya, baiknya dilakukan dalam perhitungan efisiensi exergi. Pada dasarnya, exergi pada pembangkit awalnya tinggi, namun karena ireversibilitas, terjadi rugi energi dan terdapat efek peningkatan entropi dari lingkungan, hingga pembangkit tidak lagi efektif untuk dioperasikan. Pada hal ini, lingkungan berperan terhadap exergi. Oleh karena itulah seharusnya dilakukan perhitungan berdasarkan exerginya, yaitu kemampuan untuk melakukan kerja berdasarkan teoritis [1]. Mengetahui exergi sebuah pembangkit penting, sehingga dapat dilakukan rekayasa agar memperlambat penurunan exergi. Selain itu, dapat pula diidentifikasi sumber ketidakefisienan, menentukan lokasinya dan besarnya kerugian exergi yang terjadi. Selain itu, hal lain yang perlu diperhatikan adalah menentukan kondisi kerja pembangkit yang paling optimal agar dapat mencapai nilai efisiensi paling tinggi [2]. Dan juga dapat memprediksi keuntungan finansial yang bisa bertahan

Salah satu komponen yang sangat berpengaruh dalam hasil dari kerja pada pembangkit adalah turbin. Turbin adalah suatu mesin penggerak dimana energi fluida kerja, dalam hal ini adalah uap, dipergunakan langsung untuk memutar roda turbin [3]. Turbin uap terdiri dari beberapa bagian utama [4]. Pada turbin sendiri, teradapat aliran fluida masuk berupa uap dari panas bumi. Fluida tersebut akan memutarkan sudu pada turbin dan menghasilkan kerja. Selanjutnya fluida tersebut akan keluar dari turbin. Pada proses tersebut terdapat hubungan dengan exergi antara kedua aliran. Perpindahan panas antara turbin dan sekitarnya diabaikan. Analisis exergi seperti ini dapat diaplikasikan pada banyak macam turbin $[5,6]$.

Pada penelitian ini, perhitungan exergi akan dilakukan pada komponen turbin pada saat empat musim. Ini dikarenakan turbin merupakan komponen yang terhubung dengan generator yang nantinya akan mengubah energi gerak menjadi listrik, sehingga turbin berperan besar dalam proses perubahan energi tersebut. Dan juga dikareanakan keadaan musim yang berbeda-beda, maka suhu lingkungan akan berbeda-beda pula. Sehingga bisa dilihat apa pengaruh dari perbedaan suhu lingkungan terhadap exergi yang ada pada turbin.

\section{Metode Penelitian}

Pada model penelitian ini, yang dilakukan pertama kali adalah pengamatan lapangan dan pengambilan data lapangan. Pada tahap ini, data yang didapat berupa suhu dan tekanan pada inlet dan outlet turbin untuk setiap musim. Dan juga mengetahui berapa besar kerja yang dihasilkan oleh turbin, dan juga kecepatan dan massa fluida yang mengalir di turbin. Lalu dengan data tekanan dan suhu yang didapatkan pada turbin, maka dicari nilai entalpi dan entropi untuk inlet dan outlet turbin dengan menggunakan tabel termodinamika A-4 pada inlet turbin, dan tabel A-2 untuk outlet trubin. Setelah itu dilakukan pengolahan data untuk mendapatkan nilai exergi dengan persamaan-persamaan berikut.

$$
\mathrm{e}_{1,2}=\left(h_{1}-h_{2}\right)-T_{0}\left(s_{1}-s_{2}\right)+\left(\frac{V_{1}^{2}-V_{2}^{2}}{2}\right)
$$

Lalu untuk exergi destruction yaitu:

$$
I \equiv T_{\mathrm{n}}\left(s_{2}-s_{1}\right)
$$


Dan untuk mencari efisiensi exergi digunakan persamaan:

$$
\eta=\mathrm{W} / \mathrm{E}_{1,2} \times 100 \%
$$

$\mathrm{e}_{1,2}=$ exergi pada turbin $(\mathrm{kj} / \mathrm{kg}), \mathrm{I}=$ exergi destruciton $(\mathrm{kj} / \mathrm{kg}), \eta=$ efisiensi fungsional exergi, $\mathrm{h}_{1}=$ entalpi inlet turbin $(\mathrm{kj} / \mathrm{kg}), \mathrm{h}_{2}=$ entalpin outlet turbin $(\mathrm{kj} / \mathrm{kg}), \mathrm{T}_{0}=$ suhu lingkungan $(\mathrm{K}), \mathrm{s}_{1}=$ entropi inlet turbin $(\mathrm{kj} . \mathrm{K} / \mathrm{kg}), \mathrm{s}_{2}=$ entroppi outlet trubin $(\mathrm{kj} . \mathrm{K} / \mathrm{kg}), \mathrm{V}_{1}=$ kecepatan fluida di inlet trubin $(\mathrm{m} / \mathrm{s}), \mathrm{V}_{2}=$ keceapatn fluida pada oultet turbin $(\mathrm{m} / \mathrm{s})$, dan $\mathrm{W}=$ daya turbin $(\mathrm{kj} / \mathrm{kg})$.

\section{Hasil dan Pembahasan}

Tabel 1. Hasil Pengamatan Lapangan

\begin{tabular}{ccccc}
\hline & Suhu (C) & $\mathrm{h}(\mathrm{kj} / \mathrm{kg})$ & $\mathrm{s}(\mathrm{kj} . \mathrm{K} / \mathrm{kg})$ & $\mathrm{v}(\mathrm{m} / \mathrm{s})$ \\
\hline Inlet & 440 & 3321.5 & 7.052 & 170 \\
Outlet & 110 & 2691.5 & 7.2387 & 110 \\
\hline
\end{tabular}

Lalu diketahui bahwa kerja yang dihasilkan oleh turbin adalah $500 \mathrm{kj} / \mathrm{kg}$. Berdasarkan Tabel 1, dilakukan perhitungan besar nilai exergi dengan menggunakan persamaan 1, besar exergi destruction dengan persamaan 2 dan efisiensi fungsional exergi dengan persamaan 3. Sehingga didapatkan

Tabel 2. Hasil Pengolahan Data

\begin{tabular}{cccccccc}
\hline & T0 (C) & $\begin{array}{c}\mathrm{Q} / \mathrm{m} \\
(\mathrm{kj} / \mathrm{kg})\end{array}$ & T0 (K) & $\begin{array}{c}\mathrm{e} 1,2 \\
(\mathrm{kj} / \mathrm{kg})\end{array}$ & $\begin{array}{c}\mathrm{Eq} / \mathrm{m} \\
(\mathrm{kj} / \mathrm{kg})\end{array}$ & $\begin{array}{c}\mathrm{I} / \mathrm{m} \\
(\mathrm{kj} / \mathrm{kg})\end{array}$ & $\eta(\%)$ \\
\hline $\begin{array}{c}\text { musim } \\
\text { dingin }\end{array}$ & 7.4 & & 280 & 690.751 & 19.546 & 121.204 & 81.942 \\
$\begin{array}{c}\text { musim } \\
\text { panas }\end{array}$ & 26.7 & & 300 & 694.354 & 14.807 & 129.547 & 80.936 \\
musim & 18.4 & & 291 & 692.804 & 16.845 & 125.959 & 81.365 \\
semi & & & & & & & \\
musim & 22.9 & & 296 & 693.645 & 15.740 & 127.904 & 81.132 \\
gugur & & & & & & & \\
\hline
\end{tabular}




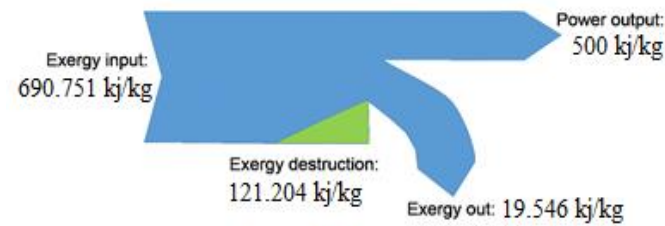

(a)

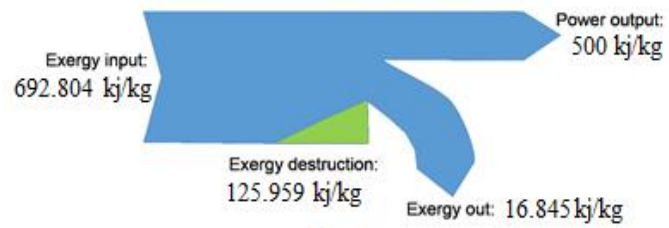

(c)

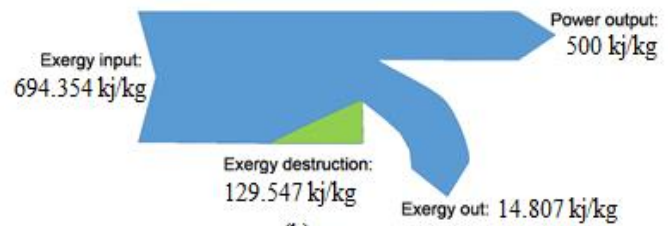

(b)

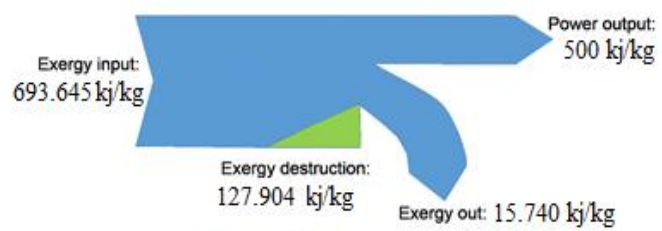

(d)

Gambar 1. Diagram mengenai aliran exergi pada turbin untuk musim :

(a) dingin, (b) panas, (c) semi, (d) gugur

Berdasarkan Gambar 1 yaitu hasil perhitungan, didapatkan bahwa adanya pengaruh keadaan lingkungan terhadap besar nilai exergi, ataupun besarnya exergi yang hilang (exergi destruction). Dan juga nilai efisiensi pun menjadi berbedabeda pula untuk setiap musim. Didapatkan untuk musim dingin, nilai exergi adalah $690.751 \mathrm{kj} / \mathrm{kg}$ dengan exergi hilang $121.204 \mathrm{kj} / \mathrm{kg}$ dan efisiensi $81.942 \%$. Lalu pada musim panas, nilai exergi adalah $694.354 \mathrm{kj} / \mathrm{kg}$ dengan exergi hilang $129.547 \mathrm{kj} / \mathrm{kg}$ dan efisiensi $80.936 \%$. Pada musim semi, nilai exergi adalah $692.804 \mathrm{kj} / \mathrm{kg}$ dengan exergi hilang $125.959 \mathrm{kj} / \mathrm{kg}$ dan efisiensi $81.365 \%$. Dan terakhir pada musim gugur, nilai exergi adalah $693.645 \mathrm{kj} / \mathrm{kg}$ dengan exergi hilang $127.904 \mathrm{kj} / \mathrm{kg}$ dan efisiensi $81.132 \%$. Terlihat bahwa semakin panas suhu dari lingkungan dapat menghasilkan exergi yang besar. Ini didasarkan karena berdasarkan persamaan 1, nilai entropi 2 lebih besar dari pada entropi 1, sehingga hasil pengurangan adalah minus, dan jika dikalikan dengan suhu lingkungan yang lebih besar, maka exergi semakin besar pula. Namun, tidak berarti bahwa semakin besar exergi adalah suatu hal yang bagus. Ini dikarenakan dalam perhitungan exergi, diperhatikan pula besarnya exergi yang hilang atau exergi destruction, yang mana semakin besar exergi destruction, maka kemungkinan exergi hilang akan semakin cepat. Exergi destrucion ini diakibatkan karena adanya faktor irreversibilitas yaitu tidak ada kemungkinan bahwa sistem akan kembali ke keadaan semulanya. Ini didasarkan oleh hukum termodinamika ke dua yaitu kalor bergerak dari sistem dengan suhu tinggi ke rendah secara spontan dan tidak sebaliknya. Karena tidak mungkin terjadi keadaan sebaliknya inilah irreversibilitas muncul. Lalu kemungkinan lain adalah karena adanya gesekan fluida terhadap permukaan pada turbin, sehingga energi dari fluida berkurang dan akhirnya exergipun hilang. Sehingga, berdarkan persamaan 3, keadaan yang baik adalah ketika suhu lingkungan yang kecil karena akan menghasilkan exergi destruction yang lebih kecil. Dan juga terlihat pada hasil perhitungan dimana ketika musim dingin yang memiliki suhu lebih kecil memiliki exergi destruction yang lebih kecil.

Lalu berdasarkan besarnya efisiensi exergi, didapatkan untuk musim dingin, besar efisiensi adalah $81.942 \%$. Lalu pada musim panas, besar nilai efisiensi $80.936 \%$. Pada musim semi memiliki efisiensi sebesar $81.365 \%$. Dan terakhir pada musim gugur, besar efisiensi adalah $81.132 \%$. Terlihat bahwa musim dingin adalah 
keadaan dengan efisiensi yang lebih besar. Ini dikarenakan, pada musim dingin walaupun dengan besar exergi kecil, karena besar kerja yang dihasilkan selalu sama yaitu $500 \mathrm{kj} / \mathrm{kg}$, maka exergi yang terpakai menjadi kerja pada musim dingin lebih banyak dari pada musim-musim lain yang memiliki exergi lebih besar, namun tetap menghasilkan kerja $500 \mathrm{kj} / \mathrm{kg}$. Sehingga pada musim dingin memiliki efisiensi yang lebih besar. Untuk perbandingan, bisa terlihat pada Gambar 1.

\section{Kesimpulan}

Nilai exergi untuk setiap musim yaitu: untuk musim dingin $690.751 \mathrm{kj} / \mathrm{kg}$, musim panas $694.354 \mathrm{kj} / \mathrm{kg}$, musim semi $692.804 \mathrm{kj} / \mathrm{kg}$, musim gugur $693.645 \mathrm{kj} / \mathrm{kg}$. Lalu didapatkan nilai exergi yang hilang untuk setiap musim yaitu: untuk musim dingin $121.204 \mathrm{kj} / \mathrm{kg}$, musim panas $129.547 \mathrm{kj} / \mathrm{kg}$, musim semi $125.959 \mathrm{kj} / \mathrm{kg}$, musim gugur $127.904 \mathrm{kj} / \mathrm{kg}$. Terlihat bahwa terdapat pengaruh suhu lingkungan pada setiap musim terhadap besar exergi dan exergi destruction (exergi yang hilang). Berdasarkan perhitungan, keadaan yang bagus adalah ketika musim dingin karena efisiensi yang besar dan exergi destruction yang kecil.

\section{Daftar Pustaka}

1. A. A. Osman, Increased Exergetic Efficiency by Using a Back Pressure Turbine for High Wellhead Pressures at Hellisheidi Geothermal Power Plant. Ministry of Water Resources and Electricity Renewable and Alternative Energy Directorate Geothermal Energy Department Vol. 28 (2014) p. 595614.

2. Nasruddin, P Satrio, Analisa Energi, Exergi dan Optimasi pada Pembangkit Listrik Tenaga Uap Super Kritikal 660 MW. Banjarmasin. Proceeding Seminar Nasional Tahunan Teknik Mesin XIV (2015) (SNTTM XIV).

3. Anonim. Chapter II http: //repository.usu.ac.id/bitstream/handle/ 123456789/ 24549/Chapter\%20II.pdf;jsessionid=0D7EAC61484F05AF1FDFEF47B1D51 52D?sequence $=4$ (diakses pada tanggal 24 Juli 2018 pukul $21.38 \mathrm{WIB}$ )

4. Anonim. 2010. Turbin Uap. Indonesian Power : UBP Priok.

5. R. Dipippo, Geothermal Power Plants : principles, applications, case studies and environmental impact. 2nd ed.Walthan. MA, USA: Elsevier, Ltd (2008).

6. C. Mulyana, N. Luthfi, A. H. Saad, Model Pendayagunaan Energi Geotermal Entalpi Rendah (Direct Use) di Jawa Barat, Jurnal Ilmu dan Inovasi Fisika Vol. 01 No. 01 (2017) p.11-23. 